\title{
A comparative study of low dose magnesium sulphate therapy with standard pritchard's regime in the management of eclampsia
}

\section{Swarnalatha Mohanapu*, Sajeethakumari Raveendran, Yogashalini Murugaiah, Maitrayee Sen}

Department of Obstetrics and Gynecology, SRM Medical College Hospital and Research Centre, Kanchipuram, Tamilnadu-603203, India

Received: 11 August 2016

Accepted: 16 August 2016

\section{*Correspondence:}

Dr. Mohanapu Swarnalatha,

E-mail: lathamadhavakrishna@gmail.com

Copyright: () the author(s), publisher and licensee Medip Academy. This is an open-access article distributed under the terms of the Creative Commons Attribution Non-Commercial License, which permits unrestricted non-commercial use, distribution, and reproduction in any medium, provided the original work is properly cited.

\section{ABSTRACT}

Background: Eclampsia is one of the most serious and potentially catastrophic complications of pregnancy and still remains a common cause of maternal and perinatal mortality and morbidity in India. Magnesium sulphate is the main stay of treatment in eclampsia and imminent eclampsia. As the margin of safety between therapeutic and toxic levels of magnesium sulphate is narrow, monitoring the serum magnesium levels to assess the criticality of situation is an uphill task in our hospitals, there is a need for modification of dosage of magnesium sulphate in tropical countries. This study compared the efficacy and toxicity of low dose magnesium sulphate regime with the standard pritchard's regime in eclampsia.

Methods: 50 cases of eclampsia were treated with low dose magnesium sulphate and 50 cases of eclampsia with standard Pritchard's regime. The recurrence rate of convulsions and magnesium toxicity were analysed.

Results: It was observed that with low dose magnesium sulphate regime, convulsions were controlled in $90 \%$ of the cases. With standard pritchard's regime convulsions were controlled in $96 \%$ of patients. The maternal and perinatal mortality and morbidity were comparable in both groups.

Conclusions: Low dose magnesium sulphate therapy is as effective as Pritchard's regime for controlling convulsions in eclampsia.

Keywords: Eclampsia, Low dose magnesium sulphate, Pritchard's regime, Toxicity

\section{INTRODUCTION}

Eclampsia is one of the most serious and potentially catastrophic complications of pregnancy and still remains the second most common cause of maternal and perinatal mortality \& morbidity in developing countries like India. Eclampsia is defined as that condition in which maternal convulsions or coma develop as a consequence of pregnancy induced or aggravated hypertension. ${ }^{1}$ It can kill the mother and the fetus unless expertly managed.

Eclampsia is a preventable disease and it is now a rare disease in developed countries with an incidence of approximately 1:2000 and 1:4000 deliveries. ${ }^{2}$ Efficient antenatal care has almost eliminated this disease in countries where such care is available and is utilised by pregnant mothers. ${ }^{3}$

But in developing countries like ours, particularly in rural areas the picture is radically different where eclampsia may present for treatment after having had many fits at home. It forms one of the deadly triad of maternal mortality and morbidity along with haemorrhage and infection. Incidence of eclampsia ranges from 1:100 to 1:1700 deliveries. Pre-eclampsia and eclampsia account for $20 \%$ of maternal deaths in India. 
The first and foremost principle in management of eclampsia is to control convulsions and expidate delivery. ${ }^{5}$ Following publication of collaborative eclamptic trial, magnesium sulphate has become the main stay of treatment in eclampsia and imminent eclampsia. Magnesium doesnot cause any significant maternal and neonatal central nervous system depression when used properly. ${ }^{6}$ The standard magnesium sulphate regime, pritchard's regime has been advocated and used since time immemorial and has shown to be very effective in controlling convulsions and thus this regime has continued to retain its popularity among obstetricians world over. This credit of popularizing magnesium sulphate regime goes to its inventor Dr. J.A. Pritchard.

Pritchard et al suggested that the dose of magnesium sulphate should be limited in women who appear to be small. Magnesium sulphate is not an innocuous drug. Administering pritchard's regime in standard doses in small or medium built women might prove to be hazardous with the potential risk of respiratory failure. ${ }^{7}$ As the margin of safety between therapeutic and toxic levels of magnesium sulphate is narrow, monitoring the serum magnesium levels to assess the criticality of situation is an uphill task in our hospitals because of infrastructure constraints. ${ }^{8}$ Keeping this in mind, there is a need for modification of dosage of magnesium sulphate deviating from the standard regime for these women in tropical countries who are diminutive in physique and weight compared to their western counter parts. The aim of the study was to compare the efficacy of low dose magnesium sulfate regime with the standard Pritchard's regime for control of convulsions in eclampsia in Indian women and to compare the incidence of toxicity of magnesium sulfate with standard Pritchard's regime and with low dose magnesium sulfate regime.

\section{METHODS}

This study was conducted in a tertiary care hospital, South India for a period of two years. This is a prospective comparative study. Patients with eclampsia who were admitted in this hospital during the study period were included. Patients with a doubtful history and those who had received anticonvulsant treatment before admission to the hospital were excluded from the study. Eclampsia patients were randomly divided into two groups. Group A included 50 cases of eclampsia who were treated with low dose magnesium sulphate therapy. Group B included 50 cases of eclampsia who were treated with Pritchard's regime.

The groups A and B were more or less comparable as regards to age, socioeconomic status, parity, type of eclampsia, duration of eclamptic state as well as number of convulsions before the start of treatment.

On admission a detailed history was taken from the patients' attendants followed by a complete physical examination and an obstetric examination.
In all patients, investigations like hemoglobin, blood grouping and Rh typing, blood urea, blood sugar, serum creatinine, serum uric acid, bleeding time, clotting time, platelet count, liver function tests, fundoscopy and complete urine examination were done.

Women in Group-A were treated with low dose magnesium sulphate with a loading dose of 4 gms magnesium sulfate i.v. diluted in $20 \mathrm{cc}$ of normal saline, given slowly over a period of 15 to 20 minutes followed by maintenance dose of 2 gms of magnesium sulfate i.m. three hourly into alternate buttocks till 24 hours after delivery or after the last convulsion whichever was later. If convulsions occurred half an hour after the loading dose, it was called recurrence of convulsions and in that cases an additional dose of $2 \mathrm{gm}$ i.m. was given and previous dose schedule of three hourly injection was continued.

Women in Group-B were treated with Pritchard's regime with a loading dose of $4 \mathrm{gms}$ magnesium sulfate i.v., diluted in $20 \mathrm{cc}$ of normal saline, given slowly over a period of 5 minutes followed by $10 \mathrm{gms}$ of magnesium sulfate deep intramuscularly and maintenance dose of 5 gms of magnesium sulfate i.m. into alternate buttocks 4th hourly till 24 hours after delivery or after last convulsion whichever was later.

Every patient was kept on an indwelling catheter. Input and output chart maintained. Every time before giving maintenance dose the following parameters were checked for magnesium sulphate toxicity.

- Deep tendon reflexes.

- Urine output.

- Respiratory rate.

The subsequent dose was administered if deep tendon reflexes (patellar reflex-knee jerk) were present, respiratory rate approximately 16 beats/minute or more and if the urine output was more than $100 \mathrm{ml}$ in the preceding 4 hours.

The antihypertensives used were $\alpha$-methyldopa and nifedipine. They were given orally as an adjuvant therapy in patients who had systolic BP $>160 \mathrm{mmHg}$ or diastolic BP $>110 \mathrm{mmHg}$ to prevent cerebrovascular accidents. Hydration was maintained by ringer lactate solution $1000 \mathrm{ml}$ over 24 hours and intravenous fluids were restricted to prevent circulatory overload. Patients were encouraged to take fluids orally as soon as they recovered consciousness.

Termination of pregnancy was undertaken in all cases of eclampsia. Delivery was expedited by induction with oxytocin or prostaglandins or with ARM as per her uterine contractions and bishop's score. During labour close watch was kept on any recurrence of convulsions and condition of the fetus. LSCS was done if there was 
any obstetric indication, uncontrolled convulsions or impending renal failure.

\section{RESULTS}

The study and control groups were comparable in respect of age, parity, religion, social economic status, period of gestation. Average weight was $48 \pm 6 \mathrm{~kg}$ in both groups. In this study in Group-A, 58\% of the patients had antepartum, $36 \%$ of the patients had intrapartum, while $6 \%$ had postpartum eclampsia. In Group-B also $60 \%$ of the patients had antepartum, $34 \%$ of the patients had intrapartum while $6 \%$ had postpartum eclampsia as shown in Table 1. As precise diagnosis of the onset of labour was not easily ascertainable and eclampsia per se increases uterine contractility and leads to premature labour, a discrete overlap between antepartum and intrapartum cases might exist in this study.

Table 1: Type of eclampsia.

\begin{tabular}{|lllll|}
\hline $\begin{array}{l}\text { Type of } \\
\text { eclampsia }\end{array}$ & Group-A & $\%$ & Group-B & $\%$ \\
\hline Antepartum & 29 & $58 \%$ & 30 & $60 \%$ \\
\hline Intrapartum & 18 & $36 \%$ & 17 & $34 \%$ \\
\hline Postpartum & 3 & $6 \%$ & 3 & $6 \%$ \\
\hline
\end{tabular}

In the present study, $80 \%$ of patients in Group-A and $76 \%$ of patients in Group-B had 1-6 convulsions while $20 \%$ in Group-A and 24\% in Group-B had more than 7 convulsions (Table 2). About 64/\% in Group-A and 60\% of Group-B patients were admitted within 6 hours after the onset of fits. About $90 \%$ of patients in group-A and 92\% of patients in Group-B were admitted within 12 hours (Table 3). Majority of these patients were from interior villages and had no access to medical services and used primitive transport facilities to reach hospital. Prognosis of a case of eclampsia often depends on how soon a case is admitted in a hospital after the onset of fits.

Table 2: Number of convulsions.

\begin{tabular}{|lllll|}
\hline $\begin{array}{l}\text { Number of } \\
\text { convulsions }\end{array}$ & Group-A & $\%$ & Group-B & $\%$ \\
\hline $1-6$ & 40 & $80 \%$ & 38 & $76 \%$ \\
\hline$>7$ & 10 & $20 \%$ & 12 & $24 \%$ \\
\hline
\end{tabular}

Table 3: Duration of eclamptic state before the start of treatment.

\begin{tabular}{|lllll|}
\hline Duration & Group-A & $\%$ & Group-B & $\%$ \\
\hline 1/2 hour to 6 hours & 32 & $64 \%$ & 30 & $60 \%$ \\
\hline 6-12 hours & 13 & $26 \%$ & 16 & $32 \%$ \\
\hline 12-18 hours & 5 & $10 \%$ & 4 & $8 \%$ \\
\hline 18-24 hours & - & - & - & - \\
\hline 2-6 days & - & - & - & - \\
\hline
\end{tabular}

In Group-A, the convulsions were controlled with loading dose itself in 45 cases i.e., $90 \%$ of patients, while two patients i.e., $4 \%$ had recurrence of one convulsion 6 and 4 hours after administration of loading dose and three patients i.e., $6 \%$ had recurrence of two convulsions 8,7 and 4 hours after administration of loading dose which were effectively controlled with an additional dose of magnesium sulfate of $2 \mathrm{gm}$-IM.

In group-B, the convulsions were controlled with loading dose in 48 cases i.e., $96 \%$ of patients, while one patient i.e., $2 \%$ had one recurrent convulsion and in another case there was recurrence of the convulsions twice. So the present study showed a recurrence rate of $10 \%$ with low dose magnesium sulfate therapy and $4 \%$ with pritchard's regime (Table 4).

Table 4: Recurrence of convulsions.

\begin{tabular}{|lll|ll|}
\hline $\begin{array}{l}\text { Recurrence of } \\
\text { convulsions }\end{array}$ & Group-A & $\%$ & Group-B & $\%$ \\
\hline None & 45 & $90 \%$ & 48 & $96 \%$ \\
\hline One & 2 & $4 \%$ & 1 & $2 \%$ \\
\hline Two & 3 & $6 \%$ & 1 & $2 \%$ \\
\hline Three or more & - & - & - & - \\
\hline
\end{tabular}

Table 5: Magnesium sulfate toxicity.

\begin{tabular}{|lll|ll|}
\hline Adverse effects & Group-A & Group-B & $\%$ \\
\hline $\begin{array}{l}\text { Flushing, sweating, } \\
\text { hypotension }\end{array}$ & - & - & - & - \\
\hline $\begin{array}{l}\text { Absent DTR } \\
\text { (knee jerk) }\end{array}$ & - & - & 3 & $6 \%$ \\
\hline Respiratory paralysis & - & - & - & - \\
\hline Injection abscess & - & - & - & - \\
\hline
\end{tabular}

In Group-A, $26 \%$ of the patients delivered by instrumental vaginal delivery, $54 \%$ of the patients delivered spontaneously and $16 \%$ of the patients underwent caesarean section. In Group-B, $32 \%$ of the patients delivered by instrumental vaginal delivery, $56 \%$ of the patients delivered spontaneously and $10 \%$ of the patients underwent caesarean section. Magnesium sulfate given for intra-partum treatment of eclampsia did not affect labour outcome. It did not alter the response to oxytocin stimulation, admission-delivery interval, duration of second stage of labour and incidence of forceps and caesarean delivery.

Depression of the newborn was seen uncommonly. It caused a small but clinically insignificant decrease in variability of the foetal heart rate. Eclamptic convulsions cause severe hypoxia and acidosis in foetus. In the present study the perinatal mortality with the availability of NICU facilities in our institution was $56 \%$ in group-A, $60 \%$ in Group-B.

Maternal mortality was $4 \%$ in group-A, and $2 \%$ in group$\mathrm{B}$ and these maternal deaths are not related to magnesium sulfate toxicity clinically. 
In the present study in Group-B, $3(6 \%)$ patients had absent knee jerks 8, 6, 10 hours after administration of loading dose. In those cases the next intramuscular maintenance dose was skipped and once the reflex was demonstrated, the intramuscular dose of magnesium sulfate was continued. But in Group-A no such drug toxicity was seen (Table 5).

\section{DISCUSSION}

Eclampsia is a life-threatening emergency that continues to be a major cause of serious maternal morbidity and mortality. Eclampsia affects $0.2 \%$ to $0.5 \%$ of all deliveries. In our hospital, the incidence of eclampsia is $1.8-2 \%$. Noor et al showed an incidence of $3.9 \%$ in his study. ${ }^{9}$ The incidence of eclampsia does not appear to have really come down. The majority of cases, of course, came from villages and mostly these patients did not have antenatal check-ups. The efficacy of magnesium sulfate in the prevention and control of eclamptic convulsions has been validated in randomized controlled trials performed worldwide. Since the introduction of Pritchard regime there has been a constant discussion in literature regarding the dose of magnesium sulfate and therapeutic serum magnesium levels.

In India pritchard's regime has been modified at many places. Different hospitals are having different regimes. A long term statistical data has not been reported and the protocol has not been standardized. Pritchard himself in 1984 suggested that the dose of magnesium sulfate should be limited in women who appear to be small. This study was planned to compare the efficacy of low dose magnesium sulfate regime with pritchard's regime in controlling convulsions in eclampsia in Indian women.

In the present study the average weight of the patients in both groups was $48 \pm 6 \mathrm{~kg}$ and all the other parameters were comparable. In this study convulsions were controlled in $90 \%$ of cases with loading dose of $4 \mathrm{gm}$ only, instead of $14 \mathrm{gm}$ as prescribed in pritchard's regime, and the recurrence rate of convulsion with low dose magnesiumsulfate therapy was $10 \%$. With pritchard's regime in $96 \%$ of cases convulsions were controlled and the recurrence rate is $4 \%$. Recurrence rate reported in various studies with Pritchard's regime is 9.7\%. Pritchard and Sibai both had reported a recurrence rate of $10-12 \%$ cases. Several studies showed a recurrence rate of $4-6 \%$ with low dose magnesium sulphate therapy. ${ }^{10-12}$

The recurrence rate with standard protocol reported in collaborative eclamptic trial, the largest multicentre randomized controlled trial ranged between $5.7 \%$ and 13.2\%. The two Asian studies one by Suman P et al and another by R. Begum of Dhaka have concluded that the low dose magnesium sulfate therapy is as effective as standard Pritchard's regime in the Asian Group. ${ }^{13,14}$ In this study with low dose magnesium sulfate therapy, the recurrence rate was $10 \%$ which is comparable with a study by Sardesai SP et al, where the recurrence rate was $8 \%$. Bangal $\mathrm{V}$ et al have clearly demonstrated in their studies that $94 \%$ cases of eclampsia can be controlled with low dose magnesium sulphate therapy. ${ }^{15,16}$ Ekele et al in his study demonstrated that limiting the dosage of magnesium sulphate to 14 grams loading dose (4 grams intravenous and 10 grams intramuscular) was effective in controlling fits in $92.6 \%$ of cases. ${ }^{17}$

With Pritchard's regime, 3 (6\%) patients had absent knee jerks, but no such drug toxicity was seen with low dose magnesium sulphate therapy. This is in accordance with Dasgupta who showed that magnesium toxicity was less with low dose therapy than with standard regimen. ${ }^{18}$

There is ample evidence that the dose regime needs to be modified according to patient's weight. Phuapradit W et al from Bangkok - state that "it seems appropriate to take in to account body weight when considering the dosage of drug and the regime used is appropriate for Asian women with body weight usually less than $70 \mathrm{~kg} " 19$ Witlin A in her review article on eclampsia in Clinical Obs. and Gyn. commented that "one may also speculate that magnesium sulfate dosing should vary according to the patients' weights or body mass index." 20 However this has never adequately been evaluated.

Women in India, especially from rural areas belong to low socio economic strata. They tend to have smaller weights. Administering pritchard regime might prove to be hazardous in these low weight women and there is every possibility of respiratory failure. The risk of respiratory failure greatly exceeds the risk imposed by administering small doses with slight possibility of one more convulsion. More over switching over to standard regime from the low dose protocol is simple in the event of such a need. The low dose protocol suffices to meet the requirements in small built eclamptic women with a recurrence rate of $10 \%$, as shown in this study.

In the magnesium sulfate metabolism, $50 \%$ of the infused dose is excreted in the urine when the concentration of serum $\mathrm{Mg}$ exceeds $2 \mathrm{mg} / \mathrm{dl}$. Thus even, if we give Pritchard's regime the excess of $\mathrm{Mg}$ is excreted by the kidneys. This is a strong justification for giving low dose regime. The key issue in our country is maternal transport to tertiary referral centre especially from rural areas. Therefore there is a need to start treatment at primary care level itself. The low dose magnesium sulfate therapy can be given safely by the medical officers and ANMs working at primary care level where facilities for specialized treatment for eclampsia is not available and can be administered to tide over the crisis without fear of precipitating respiratory failure before transferring the patient to a higher centre.

To conclude, low dose magnesium sulfate therapy is as effective as pritchard regime for controlling convulsions in eclampsia. The risk of developing magnesium sulfate toxicity is low with low dose magnesium sulphate 
therapy when compared to pritchard's regime in Indian women. Low dose regime can be administered safely even by the staff at primary care level without fear of precipitating respiratory failure. In years to come it may become an established treatment protocol in India and will be a major stepping stone towards the aim of safe motherhood.

\section{ACKNOWLEDGEMENTS}

The authors would like to acknowledge Dr. Shyam Anand Thirumani and Dr. Sreemukhi, of Obstetrics and Gynecology department for their help in the writing process and also the subjects who readily agreed to participate in this study.

\section{Funding: No funding sources}

Conflict of interest: None declared

Ethical approval: The study was approved by the Institutional Ethics Committee

\section{REFERENCES}

1. Ratnam SS, Rao KB, Kumar SA. Management of PIH. Obstetrics and Gynaecology of post graduates. Orient Longman. 2005;1(2):56-67.

2. Bansal V, Damania KR. Hypertensive disorders in pregnancy, Fernando Arias, Practical Guide to High Risk Pregnancy and Delivery $4^{\text {th }}$ Edition, Elsevier; 2015:218-229.

3. Gopalan S. Hypertensive disorder of pregnancy, Mudaliar and Menon's clinical obstetrics, 12 edition, Universities Press; 2015:175-179.

4. Goswami B. Journal of Postgraduate Medicine, Eclampsia in rural India. J Obstet and Gynaecol Ind. 1984;34:1012-5.

5. Cunningham FG, Leveno KJ. Hypertensive disorders. William's Obstetrics $24^{\text {th }}$ edition, Mc Graw Hill; 2010:755-770.

6. James DK, Steer PJ, Weiner CP, Gonik B. Asnat Walfisch/Mordechai Hallak, Hypertension, High Risk Pregnancy Management options, $3^{\text {rd }}$ Edition, Elsevier; 2006:784-788.

7. Malhotra B, Misra R. Hypertensive Disorder in Pregnancy Ian Donald's Practical Obstetric Problems: $6^{\text {th }}$ Edition, BI Publications; 2008:289304.

8. Baha M, Sibai. Pregnancy and co existing disease Hypertension, Steven G. Gabbe, Jennifer R. Niebyl,
Joe Leigh Simpson, Obstetrics Normal and Problem Pregnancies, $5^{\text {th }}$ Edition, Churchill Livingstone Elsevier; 2007:895-897.

9. Noor S, Halini M, Faiz NR, Gull F, Akbar N. Magnesium sulphate in the prophylaxis and treatment of eclampsia. J Ayub Med Coll Abbottabad. 2004;16(2):50-4.

10. Sahu L, Singh S, Tempe A, BC Koner. A randomised comparative study between low dose magnesium sulphate and standard dose regimen for management of eclampsia. Int J Reprod Contracept Obstet Gynecol. 2014;3(1):79-86.

11. Abdul MA, Nasir UI, Khan N, Yusuf MD. Low dose magnesium sulphate in the control of eclamptic fits, a randomised control trial. Archives Gynecol Obstet. 2013;287:43-6.

12. Jana N, Dasgupta S, Das AK, Sandra D, Samanta B. Experience of a low dose magnesium sulphate regimen for the management of eclampsia over a decade. Internat J Gyn Obstet. 2013;122(1):13-7.

13. Suman S, Patil MS, Patil U. Low dose magnesium sulphate therapy for eclampsia and imminent eclampsia regime tailored for Indian women. Jr Obst Gynaecol India. 2003;53(6):540-6.

14. Begum R, Begum A, Johanson R, Ali MN, Akhter S. A low dose (Dhaka) magnesium sulphate regime for eclampsia. Acta Obstet Gynecol. 2001;80(11):9981002.

15. Jayatinath, Sharma R, Mahajan SS. A study on low dose magnesium sulphate regime for eclampsia in a tertiary care teaching hospital in North India. Biomed Pharmacol J. 2013;6(1):29-32.

16. Bangal V, Kwatra A, Raghav S, Jadhav S. Low dose magnesium sulphate for eclampsia. Pravara Med Rev. 2009;1(3):13-5.

17. Ekele BA, Muhammed D, Bello LN, Namadina IM. Magnesium sulphate therapy in eclampsia: the Sokoto (ultra short) regimen. BMC Research Notes. 2009;2:165.

18. Dasgupta S, Sarkhel A, Jain A. Single loading dose of magnesium sulphate in severe preeclampsia and eclampsia-is it effective? a randomized prospective study. Obstet Gynecol Int J. 2015;2(6):59.

19. Winit P, Saropala N. Serum level of magnesium attained in magnesium sulphate therapy for severe preeclampsia. Asia Oceania J Obstet Gyn. 1993;194:387-90.

20. Andrea W. Prevention and treatment of eclamptic convulsions. Clinical Obstet Gyn. 1999;42:16-24.

Cite this article as: Mohanapu S, Raveendran SK, Murugaiah Y, Sen M. A comparative study of low dose magnesium sulphate therapy with standard pritchard's regime in the management of eclampsia. Int J Reprod Contracept Obstet Gynecol 2016;5:2939-43. 